\title{
Tuning the Mechanical Properties of Tapioca Starch by Plasticizers, Inorganic Fillers and Agrowaste-Based Fillers
}

\author{
Edwin Azwar and Minna Hakkarainen \\ Department of Fibre and Polymer Technology, School of Chemical Science and Engineering, \\ KTH Royal Institute of Technology, 10044 Stockholm, Sweden
}

Correspondence should be addressed to Minna Hakkarainen, minna@polymer.kth.se

Received 21 March 2012; Accepted 10 April 2012

Academic Editors: C. De Rosa, B. Hazer, J. Puiggali, and C. T. Ratnam

Copyright ( 52012 E. Azwar and M. Hakkarainen. This is an open access article distributed under the Creative Commons Attribution License, which permits unrestricted use, distribution, and reproduction in any medium, provided the original work is properly cited.

\begin{abstract}
Mechanical properties of tapioca starch-based films were tuned by different additives and additive combinations. The additives included plasticizers (glycerol, sorbitol, and citric acid), inorganic fillers (halloysite and kaolin), and agrowaste-based fillers (milled wood flour and rice bran). In addition, new biobased additives were prepared from wood flour and rice bran through liquefaction reaction. Through different additive combinations, starch-based materials with significant differences in tensile properties were designed. Addition of halloysite nanoclay resulted in materials with improved tensile strength at break and rather low strain at break. The effect of kaolin on tensile strength was highly dependent on the used plasticizer. However, in most combinations the addition of kaolin resulted in materials with intermediate tensile strength and strain at break values. The addition of milled wood flour and rice bran improved the tensile strength, while the addition of liquefied fillers especially liquefied rice bran increased the strain at break indicating that liquefied rice bran could have potential as a plasticizer for starch blends.
\end{abstract}

\section{Introduction}

There is increasing interest in replacing nondegradable packaging materials with renewable and degradable polymeric materials. Starch-based materials are among the most promising renewable materials due to being abundant, renewable, low-cost, and nontoxic materials [1]. However, the inadequate mechanical properties and hydrophilicity limit the application range of starch-based material. The development of starch nanocomposites has attracted a lot of attention as a way to improve the mechanical properties and reduce the water absorption of starch materials [2]. In most studies 2:1 clays, especially montmorillonites with different surface modifications, were used as reinforcing phase due to their ability to be exfoliated [3, 4]. 1:1 aluminosilicate clay minerals, such as modified halloysite nanotubes, as well as kaolin have also been shown to enhance the mechanical properties of starch $[5,6]$. The type of plasticizer and the organomodification of the nanoclays are important for the homogeneous distribution of the fillers and the clay exfoliation process $[7,8]$. It was also shown that blending starch and nanoclay before addition of plasticizer improved the exfoliation process [9]. This allowed the starch to penetrate the silicate layers before the plasticizer did it. Mechanical properties of starch/montmorillonite composites could be additionally enhanced by using, for example, chitosan or polyvinyl alcohol as a compatibilizer to improve the interactions between starch and nanoclays $[10,11]$.

Addition of biofibers or other biobased fillers is another attractive option to enhance the properties of starch-based materials [12]. The chemical similarities and hydrophilicity of starch and natural fillers, like wood flour, give good prerequisites for successful formation of favorable interactions between the additive and starch matrix [13]. However, chemical modification can still be necessary to improve the fiber/starch interface [14]. A combination of nanofillers and biobased fillers could offer additional possibilities for material modification [15]. As an example nano-biocomposites combining cassava starch, sugarcane bagasse fibers and montmorillonite were successfully prepared [16]. Previously we utilized agrowaste-based fillers to modify properties and 
degradation process of polylactide [17]. The purpose of the present work was to further evaluate the possibilities of using agroindustrial waste materials as fillers for common biobased materials and to tune the mechanical properties of starch through utilization of different combinations of plasticizers, mineral, and biobased fillers.

\section{Experimental}

2.1. Materials. Tapioca starch (TS) was bought from Ibu Tani, cap anak no.1, Bogor, Indonesia. Wood flour (W) and rice bran $(\mathrm{R})$ were purchased as agricultural waste from Indonesian farmers. Glycerol (G), sorbitol (S), citric acid (C), halloysite nanoclay $(\mathrm{H})$, and kaolin finest powder $(\mathrm{K})$ were purchased from Sigma-Aldrich Chemie GmbH (Steinheim, Germany).

2.2. Liquefaction of Wood Flour and Rice Bran. $80 \mathrm{~g}$ glycerol, $20 \mathrm{~g}$ diethylene glycol, and 2,3 g p-toluenesulfonic acid were placed into the three necked glass reaction vessel and heated with stirring. Wood powder or rice bran powder was added gradually after the temperature reached $160^{\circ} \mathrm{C}$, after this the temperature was further raised to $180^{\circ} \mathrm{C}$ and liquefaction was carried out for $120 \mathrm{~min}$. After the reaction vessel had cooled down, liquefied wood flour (LW) and liquefied rice bran (LR) inside the reaction vessel were diluted by dioxane/water solution $(4: 1 \mathrm{v} / \mathrm{v})$. The diluted sample was then filtered using a preweighted Whatman filter paper. The residue on the filter paper was dried at $120^{\circ} \mathrm{C}$ until constant weight. The liquefaction ratio was determined to be $84 \%$ for wood flour and $43 \%$ for rice bran. After distillation of the solvents the weight average molecular weight for the liquefied products was determined by SEC to be $380 \mathrm{~g} / \mathrm{mol}$ for liquefied wood flour and $1390 \mathrm{~g} / \mathrm{mol}$ for liquefied rice bran.

2.3. Film Preparation. The total weight of each film was adjusted to $10 \mathrm{~g}$. 5 or $6 \mathrm{~g}$ starch was weighted together with 4-5 g of different plasticizer (G, C, S), biofiller (W, R, LW, $\mathrm{LR})$, and inorganic filler $(\mathrm{H}, \mathrm{K})$ combinations according to Table 1. In addition to the tabulated compositions a large number of other compositions were prepared but they were omitted from further studies because of poor mechanical properties. All the components together with deionized water were added into a $125 \mathrm{~mL}$ erlenmeyer. The solution was heated on hot plate Haake Rheocard 600. Stirring and heating were continued for 1 hour at $90^{\circ} \mathrm{C}$ until the gelatinization of tapioca starch. The solutions were spread on a petri dish and allowed to air-dry at room temperature until most of the water was evaporated. The remaining water was then removed by placing the films in vacuum oven for 7 days at room temperature.

2.4. Characterization. Mechanical properties were measured by Instron Universal testing machine (Model 5566) equipped with pneumatic clamps and the tests performed with $500 \mathrm{~N}$ load cell and cross-head speed $4 \mathrm{~mm} / \mathrm{min}$. The software program used was Bluehill. Prior to tensile testing, all the samples were conditioned at $50 \%$ relative humidity
Table 1: Different starch, plasticizer, biofiller, and mineral filler compositions that resulted in good uniform films.

\begin{tabular}{lcccccccccc}
\hline Material & TS & G & C & S & K & H & W & R & LW & LR \\
\hline G2C2 & 6 & 2 & 2 & & & & & & & \\
G2K2 & 6 & 2 & & & 2 & & & & & \\
G2H2 & 6 & 2 & & & & 2 & & & & \\
S2H2 & 6 & & & 2 & & 2 & & & & \\
S2K2 & 6 & & & 2 & 2 & & & & & \\
G1S1K2 & 6 & 1 & & 1 & 2 & & & & \\
G2C1K1 & 6 & 2 & 1 & & 1 & & & & & \\
G2WF2 & 6 & 2 & & & & & 2 & & & \\
G2RB2 & 6 & 2 & & & & & & 2 & & \\
S3K2 & 5 & & & 3 & 2 & & & & & \\
G2C1K1RB1 & 5 & 2 & 1 & & 1 & & & 1 & & \\
G3H1WF1 & 5 & 3 & & & & 1 & & 1 & & \\
G2C1H1LRB1 & 5 & 2 & 1 & & & 1 & & & & 1 \\
G2C1H1LWF1 & 5 & 2 & 1 & & & 1 & & & 1 & \\
G2C1K1LBR1 & 5 & 2 & 1 & & 1 & & & & 1 \\
G2C1K1LWF1 & 5 & 2 & 1 & & 1 & & & 1 & \\
\hline
\end{tabular}

and $23^{\circ} \mathrm{C}$. Before test, five specimens with rectangular shape $\left(80.5 \mathrm{~mm}^{2}\right)$ were prepared by using EP $04 / 80.5 \mathrm{~mm}^{2}$ specimen cutter (Elastocon AB, Sweden). The thickness of the sample pieces was measured using a digital thickness gauge. SEM analyses were performed by Hitachi S- 4800 ultrahigh-resolution FE-SEM. All samples were examined using an accelerating voltage of $1.0-1.5 \mathrm{kV}$. The FTIR spectra were monitored by Perkin Elmer Spectrum 2000 in the range $4000-500 \mathrm{~cm}^{-1}$. The FTIR was equipped with a single reflection attenuated total reflectance crystal accessory (golden gate). Thermogravimetry analyses were carried out by a Mettler TGA851 instrument. $10 \mathrm{mg}$ of sample was put in a alumina crucible and heated in the furnace, flushed with $\mathrm{N}_{2}$ gas at the rate of $50 \mathrm{~mL} / \mathrm{min}$, from $30^{\circ} \mathrm{C}$ to $450^{\circ} \mathrm{C}$, at the rate of $10^{\circ} \mathrm{C} / \mathrm{min}$. The percentage weight loss was plotted against temperature.

\section{Results and Discussion}

Different starch compositions were prepared by varying the amount of starch, plasticizers, inorganic fillers, and biobased fillers. The compositions that resulted in good uniform films that could be removed from petri dishes without fragmentation are listed in Table 1 and were further analyzed to evaluate the effect of different fillers and filler combinations on the mechanical properties of starch films. Originally a large number of different starch and plasticizer concentrations and combinations were evaluated, but for further studies starch content was fixed to 50 or $60 \mathrm{wt} . \%$ as this generally resulted in best film properties.

3.1. The Effect of Additives on Tensile Strength at Break. Tensile strength at break for different starch compositions with 60 wt.\% starch content is shown in Figure 1. Materials 


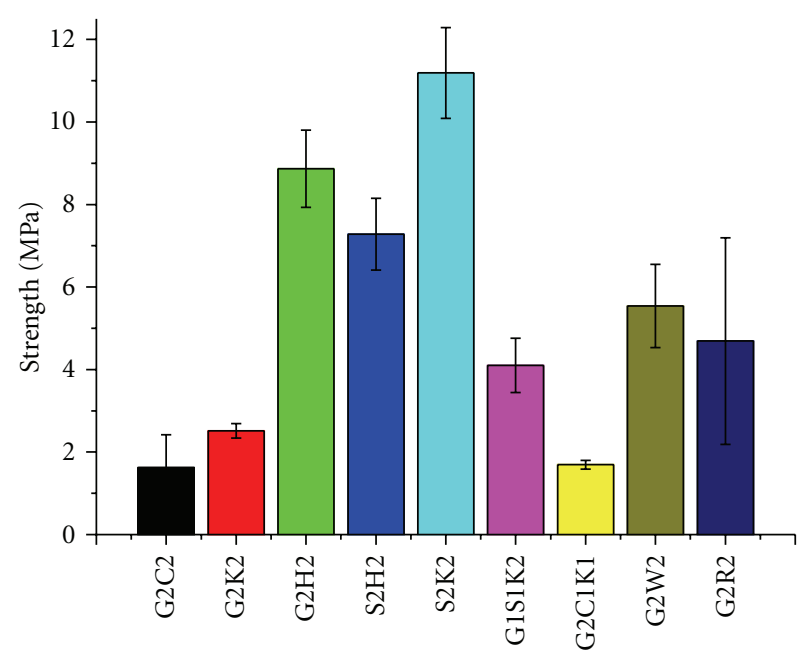

FIgURE 1: Tensile strength at break for tapioca starch modified with plasticizers (glycerol, citric acid, sorbitol), inorganic fillers (halloysite, kaolin), and/or agrowaste-based fillers (wood flour, rice bran).

G2C2 and G2C1K1 had the lowest tensile strength. This can be deduced to the largest plasticizer concentration (40 and $30 \mathrm{wt.} \%)$ in these materials. The other materials presented in Figure 1 all have 20 wt.\% plasticizers. Comparison of G2K2, G2H2, S2K2, and S2H2 shows that addition of halloysite nanofiller always led to improvement of tensile strength. However, the effect of kaolin depended on the used plasticizer. Combination of kaolin with sorbitol improved the tensile strength, while combination of kaolin with glycerol resulted in rather low tensile strength. Using 50/50 glycerol/sorbitol plasticizer mixture resulted in intermediate tensile strength values confirming the different function of sorbitol and glycerol in combination with kaolin. The generally higher tensile strength values for halloysite composites can be deduced to the needle like structure of the halloysite nanoclay. The addition of milled wood flour (G2W2) or milled rice bran (G2R2) resulted in materials with higher tensile strength compared to corresponding materials with same amount of glycerol and kaolin (G2K2) but lower tensile strength compared to the glycerol/halloysite material (G2H2).

Figure 2 presents the tensile strength for starch combinations with $50 \mathrm{wt} . \%$ starch. Decreasing the starch content to $50 \mathrm{wt} . \%$ generally decreased the tensile strength at break. However, larger mineral filler content or combination of mineral filler and milled wood flour or rice bran improved the tensile strength. The materials with glycerol/citric acid plasticizer in combination with $10 \mathrm{wt} . \%$ mineral filler and $10 \mathrm{wt} . \%$ liquefied wood flour or rice bran all had rather low tensile strengths. The replacement of liquefied rice bran with milled rice bran, however, significantly improved the tensile strength. Replacement of liquefied wood flour by milled wood flour slightly increased the tensile strength but the effect was not at all as distinct as in the case of rice bran.

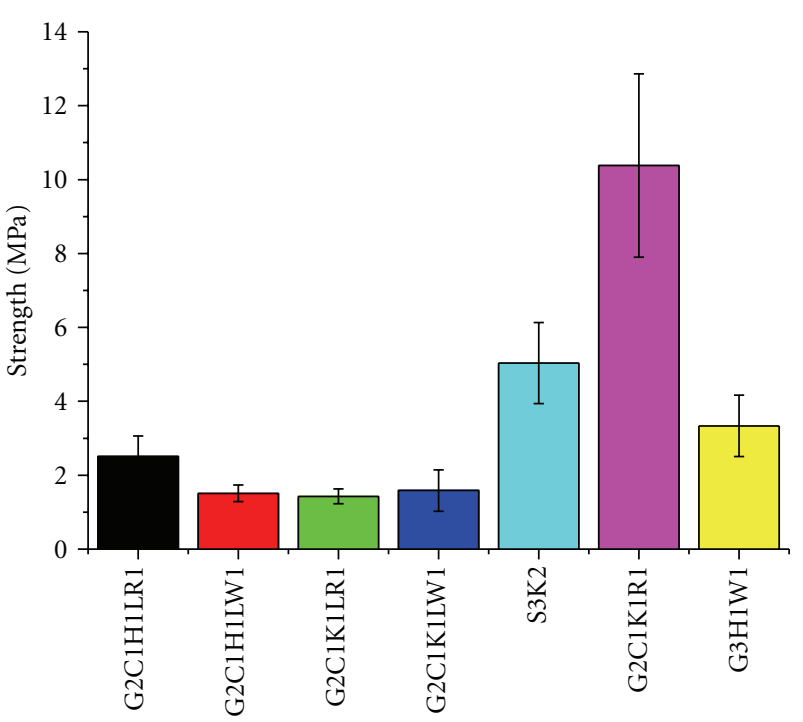

Figure 2: Tensile strength at break for tapioca starch modified with liquefied wood flour or rice bran and/or plasticizers, milled wood flour and rice bran and mineral fillers.

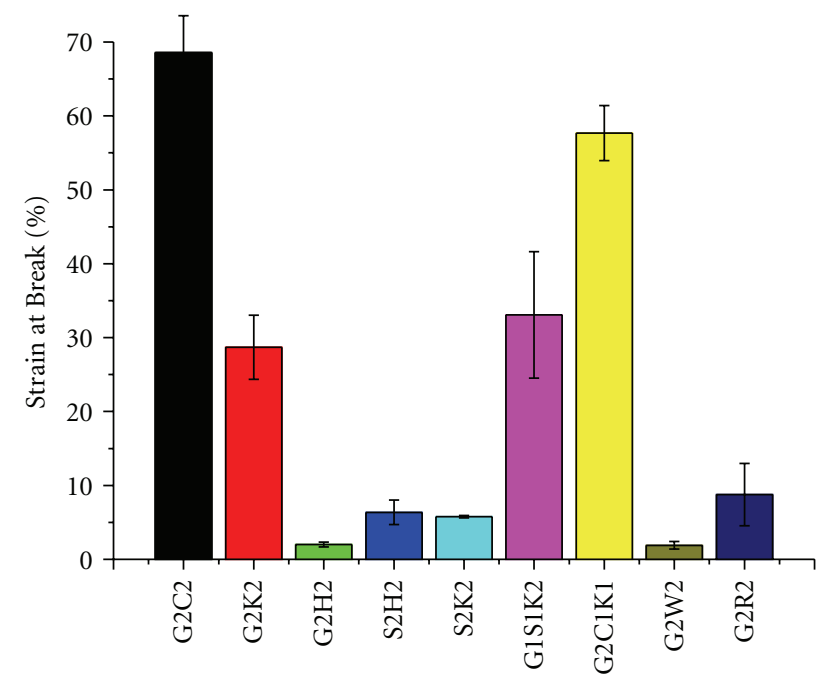

FIgURE 3: Strain at break for tapioca starch with plasticizers (glycerol, citric acid, sorbitol), inorganic fillers (halloysite, kaolin), and agrowaste-based fillers (wood flour, rice bran).

3.2. The Effect of Additives on Tensile Strain at Break. The strain at break for the films containing $60 \mathrm{wt} . \%$ of tapioca starch is presented in Figure 3. Generally, as could be expected, the materials with highest tensile strain at break were the ones exhibiting lowest tensile strength at break in Figure 1. By far best strain at break values was obtained by increasing the plasticizer concentration to 30 or $40 \mathrm{wt} . \%$. Comparison of the blends containing $20 \mathrm{wt} . \%$ plasticizers shows that low strain at break values was obtained when sorbitol was used as the only plasticizer. The combination of glycerol with halloysite, wood flour, or rice bran also resulted in low strain at break values. Interestingly, the combination 


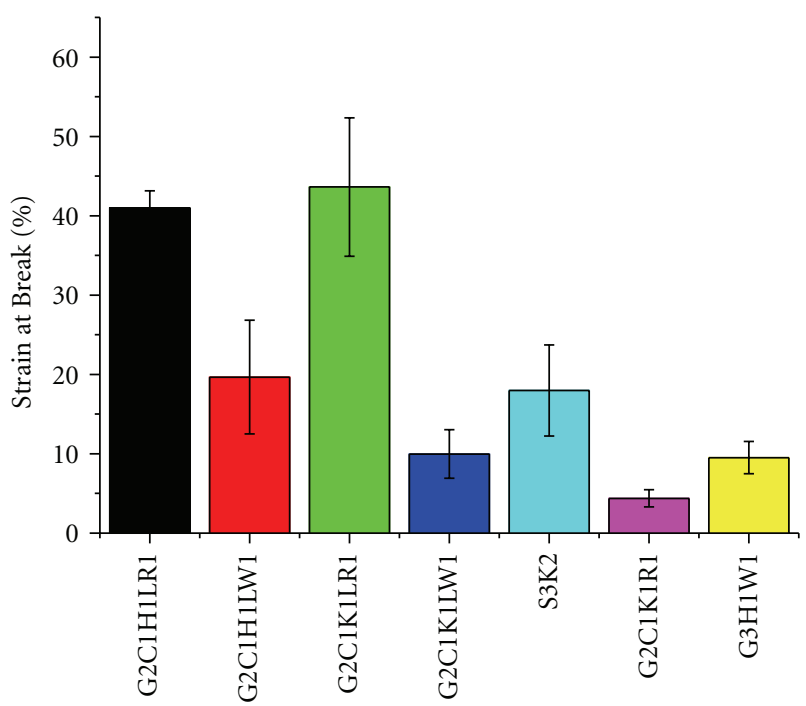

FIgURE 4: Strain at break for tapioca starch modified with liquefied wood flour or rice bran and/or plasticizers, milled wood flour and rice bran, and mineral fillers.

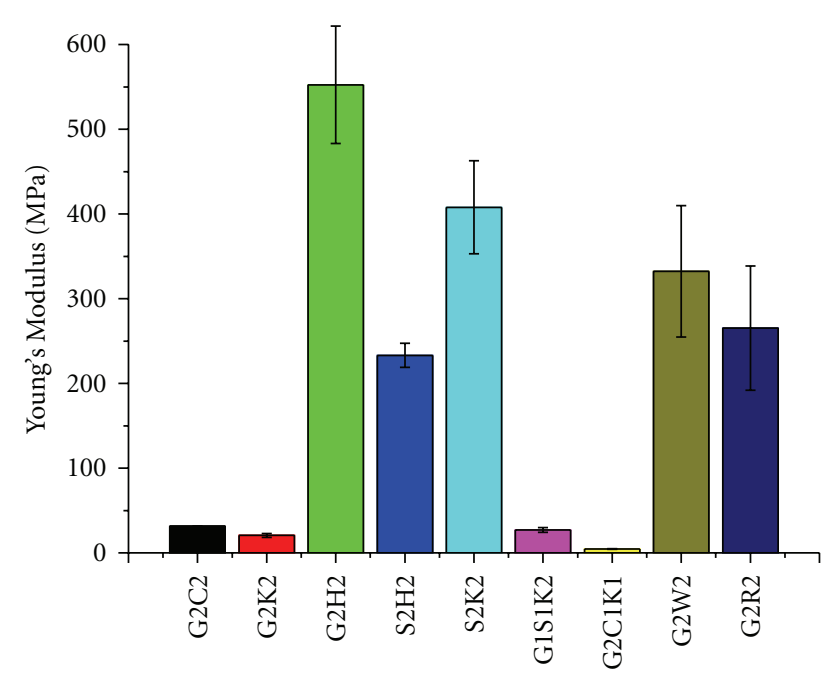

FIGURE 5: Young's modulus for tapioca starch with plasticizers (glycerol, citric acid, sorbitol), inorganic fillers (halloysite, kaolin), and biobased fillers (wood flour, rice bran).

of glycerol or glycerol/sorbitol with kaolin resulted in significantly higher tensile strain values (G2K2, G1S1K2). The addition of kaolin, thus, generally resulted in materials with intermediate strain at break and strength at break values, while other combinations could be utilized to improve either the tensile strength at break or tensile strain at break.

Comparison of the films containing $50 \mathrm{wt} . \%$ starch and $30 \mathrm{wt} . \%$ plasticizers in Figure 4 shows that the strain at break increased as the amount of plasticizers was increased. This is clearly seen by comparing S3K2 with the S2K2 in Figure 3. The best strain at break was obtained for blends containing a combination of mineral fillers and liquefied rice bran. The strain at break values for the films containing liquefied wood

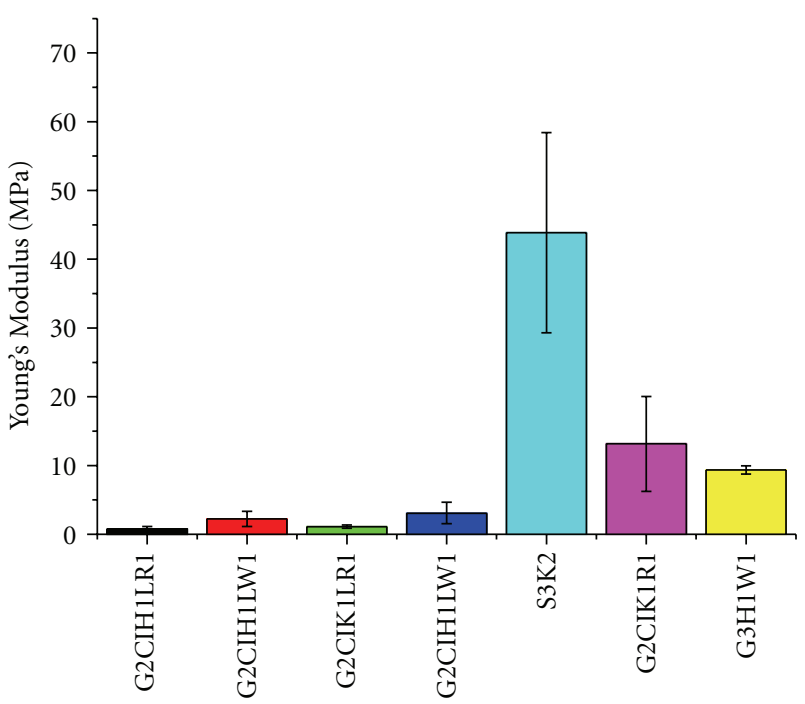

FIGURE 6: Young's modulus for tapioca starch modified with liquefied biomass (wood flour, rice bran) and/or plasticizers, untreated biofillers, and mineral fillers.

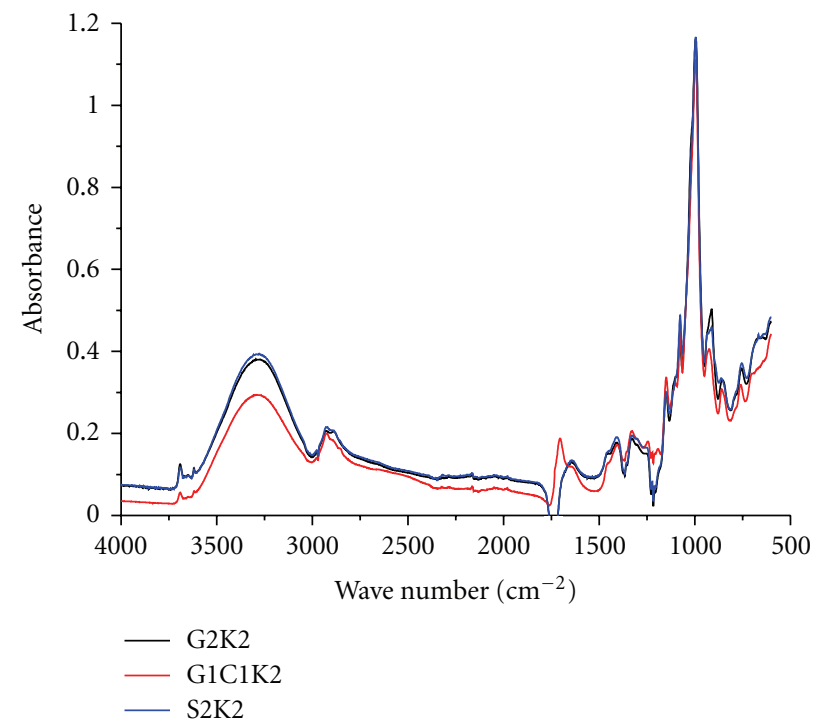

FIgURE 7: Examples of FTIR spectra for 60 wt.\% starch blends containing $20 \mathrm{wt} . \%$ kaolin and different plasticizers.

flour was only $25-50 \%$ of the corresponding liquefied rice bran films.

3.3. Young's Modulus of the Modified Films. Young's modulus values showed similar trends than the tensile strength at break values. However, the differences were even more marked (Figure 5). The kaolin composites generally had low Young's modulus, while the halloysite, milled wood flour, and rice bran composites had higher Young's modulus values. The combination of sorbitol/kaolin also increased Young's modulus compared to the glycerol/kaolin blends, which instead had much higher strain at break. Decreasing the starch content to only $50 \mathrm{wt} . \%$ significantly lowered 


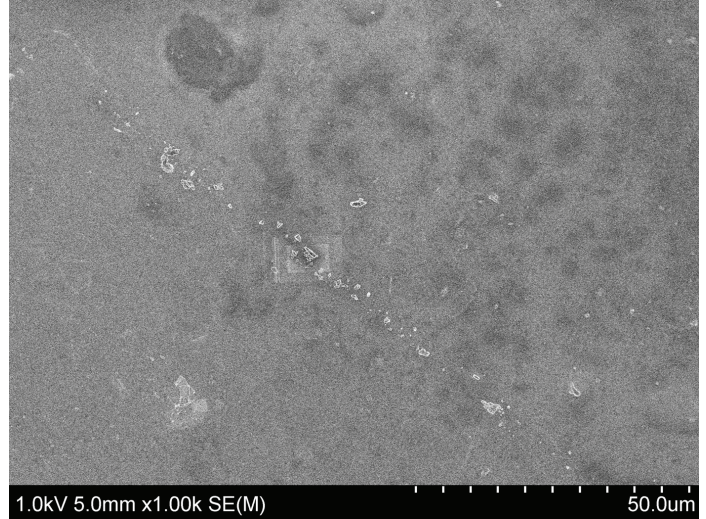

(a)

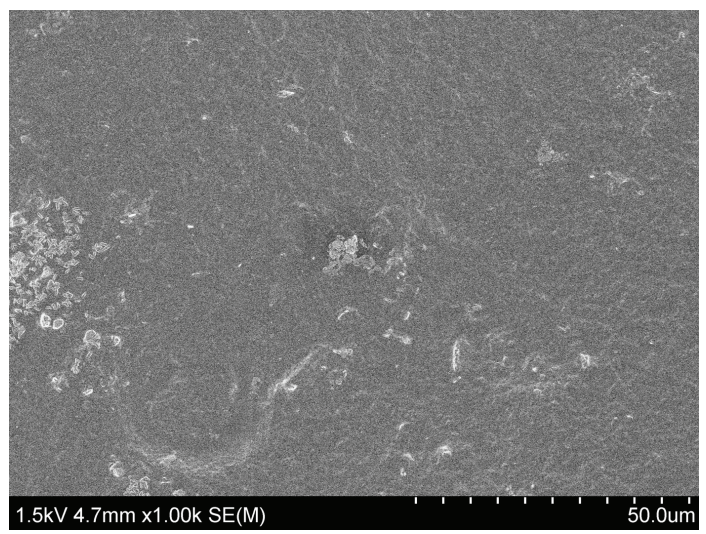

(b)

FIGURE 8: SEM images showing the surface of S3K2 (a) and G2C1K1W1 (b).

Young's modulus (Figure 6). As expected the addition of liquefied wood flour or rice bran further decreased the Young's modulus, while the composites with only mineral fillers and/or milled wood flour and rice bran exhibited higher Young's modulus values.

3.4. Surface Characterization of the Blends and Composites. The surfaces of the different starch blends and composites were characterized by FTIR and SEM. No significant differences in the surface chemistry were observed for the different blends by FTIR. Figure 7 shows as example some typical FTIR spectra of starch/mineral filler composites. The main differences consisted of differences in the hydroxyl absorption band intensity depending on the amount of starch and the nature and amount of hydroxyl groups in the additives. Appearance of carbonyl absorption band could also be observed for blends containing citric acid plasticizer.

Some agglomeration and uneven distribution of the milled wood flour, rice bran, and mineral fillers were observed by SEM (Figure 8). Dark spots in Figure 8(a) could indicate some phase separation between starch and sorbitol plasticizer, which would correlate with poor strain at break observed by SEM. The addition of liquefied fillers on

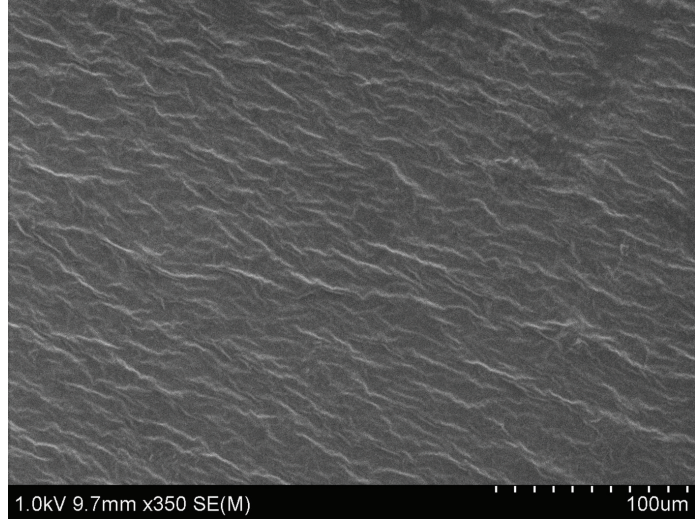

(a)

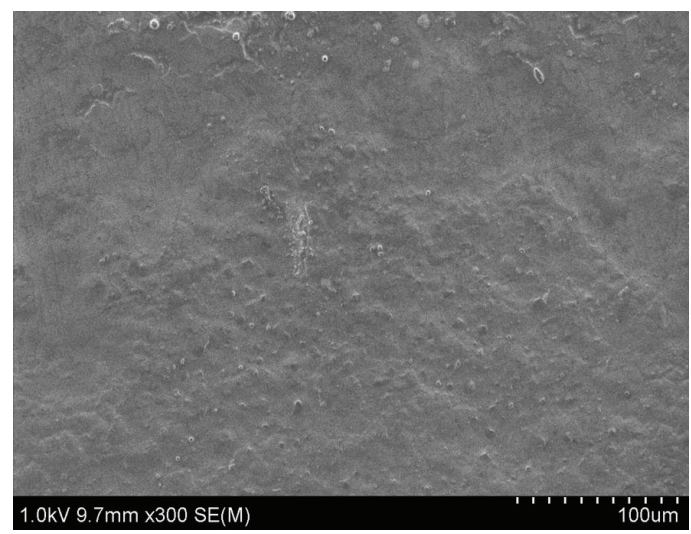

(b)

FIGURE 9: SEM images showing the surface of G2C1H1LW1 (a) and G2C1K1LW1 (b).

the other hand resulted in homogeneous surface structures (Figure 9). As an example the SEM image in Figure 10(a) showing the surface of G2C1H1LW1 is basically identical to the surface shown previously for glycerol plasticized cassava starch films [18].

3.5. Thermal Stability of the Materials. The effect of different additives on the thermal stability of the $60 \mathrm{wt} \%$ starch blends was evaluated by TGA. The onset of degradation temperatures for the different compositions was generally in the range $270-300^{\circ} \mathrm{C}$. It was somewhat difficult to deduce the effect of different components, but the addition of mineral fillers generally increased the onset of degradation and large amount of plasticizer decreased the onset of degradation probably due to evaporation of plasticizer, which started at lower temperature (see Figure 10).

\section{Conclusions}

The mechanical properties of starch blends and composites were tuned by different combinations of plasticizers, mineral fillers, and agrowaste-based additives. Halloysite, milled wood flour and rice bran improved the strength at break 


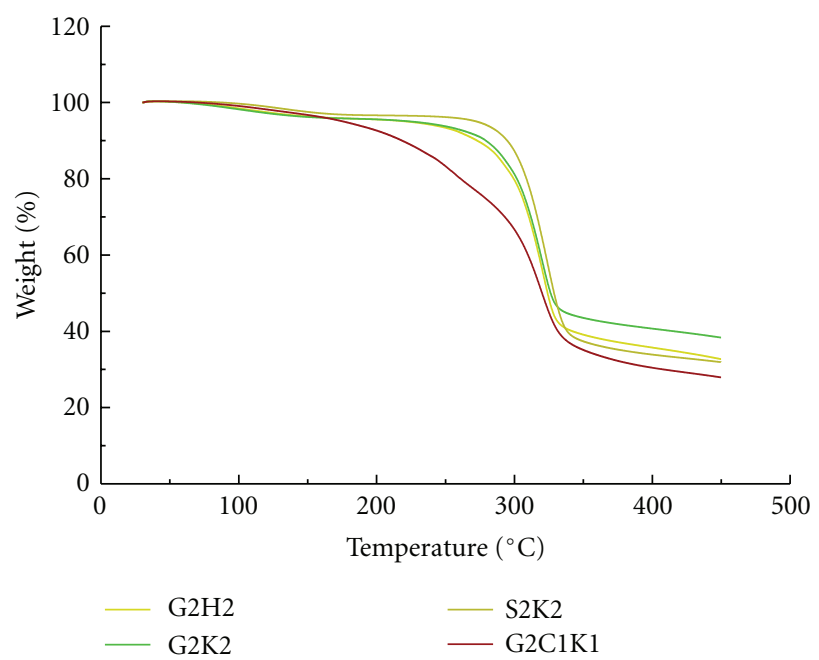

(a)

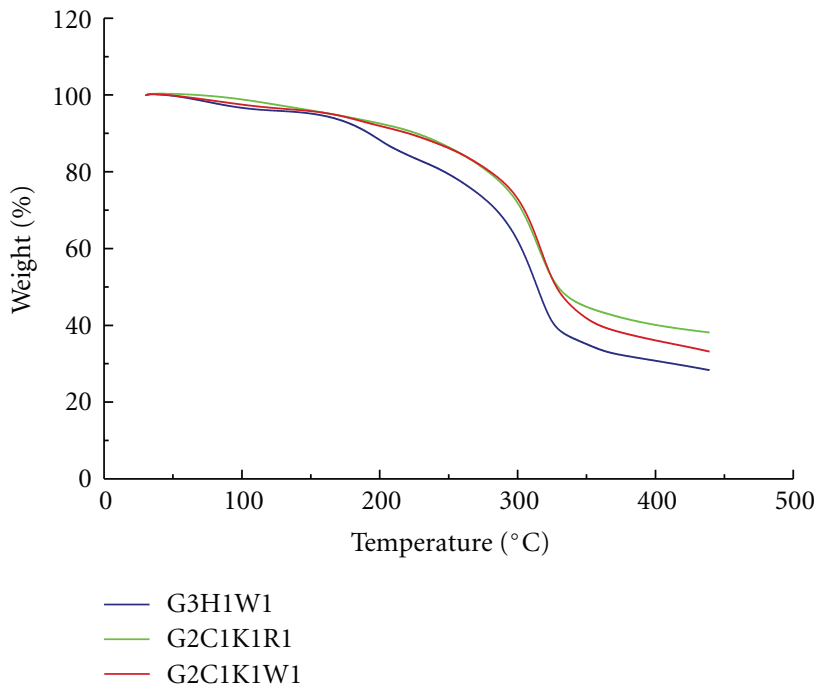

(b)

FIGURE 10: Typical TGA curves for different starch blend compositions containing different amounts of plasticizers, mineral fillers, and biobased fillers.

of the starch films, while addition of kaolin in most cases resulted in materials with intermediate strength at break and strain at break. More flexible materials were obtained by increasing the amount of traditional plasticizers glycerol, sorbitol, and citric acid. The addition of liquefied rice bran also significantly improved the strain at break indicating potential as green additive for starch.

\section{Acknowledgment}

E. Azwar gratefully acknowledges the scholarship from the Indonesian government.

\section{References}

[1] L. Avérous, "Biodegradable multiphase systems based on plasticized starch: a review," Journal of Macromolecular Science C, vol. 44, no. 3, pp. 231-274, 2004.

[2] L. Averous and N. Boquillon, "Biocomposites based on plasticized starch: thermal and mechanical behaviours," Carbohydrate Polymers, vol. 56, no. 2, pp. 111-122, 2004.

[3] N. Wang, X. Zhang, N. Han, and S. Bai, "Effect of citric acid and processing on the performance of thermoplastic starch/montmorillonite nano-composites," Carbohydrate Polymers, vol. 76, no. 1, pp. 68-73, 2009.

[4] K. Dean, L. Yu, and D. Y. Wu, "Preparation and characterization of melt-extruded thermoplastic starch/clay nanocomposites," Composites Science and Technology, vol. 67, no. 3-4, pp. 413-421, 2007.

[5] Y. He, W. Kong, W. Wang et al., "Modified natural halloysite/potato starch composite films," Carbohydrate Polymers, vol. 87, pp. 2706-2711, 2012.

[6] J. A. Mbey, S. Hoppe, and F. Thomas, "Cassava starch-kaolinite composite film, effect of clay content and modification on film properties," Carbohydrate Polymers, vol. 88, pp. 213-222, 2012.
[7] C. Zeppa, F. Gouanvé, and E. Espuche, "Effect of a plasticizer on the structure of biodegradable starch/clay nanocomposites: thermal, water-sorption, and oxygen-barrier properties," Journal of Applied Polymer Science, vol. 112, no. 4, pp. 2044-2056, 2009.

[8] F. Chivrac, E. Pollet, P. Dole, and L. Avérous, "Starch-based nanobiocomposites: plasticizer impact on the montmorillonite exfoliation process," Carbohydrate Polymers, vol. 79, no. 4, pp. 941-947, 2010.

[9] J. K. Pandey and R. P. Singh, "Green nanocomposites from renewable resources: effect of plasticizer on the structure and material properties of clay-filled starch," Starch/Staerke, vol. 57, no. 1, pp. 8-15, 2005.

[10] P. Kampeerapappun, D. Aht-ong, D. Pentrakoon, and K. Srikulkit, "Preparation of cassava starch/montmorillonite composite film," Carbohydrate Polymers, vol. 67, no. 2, pp. 155-163, 2007.

[11] K. M. Dean, M. D. Do, E. Petinakis, and L. Yu, "Key interactions in biodegradable thermoplastic starch/poly(vinyl alcohol)/montmorillonite micro- and nanocomposites," Composites Science and Technology, vol. 68, no. 6, pp. 1453-1462, 2008.

[12] A. Ueberschaer, M. E. Cagiao, R. K. Bayer, S. Henning, and F. J. Baltá Calleja, "Micromechanical properties of injectionmolded starch-wood particle composites," Journal of Applied Polymer Science, vol. 100, no. 6, pp. 4893-4899, 2006.

[13] M. Morreale, R. Scaffaro, A. Maio, and F. P. La Mantia, "Effect of adding wood flour to the physical properties of a biodegradable polymer," Composites Part A, vol. 39, no. 3, pp. 503-513, 2008.

[14] J. Duanmu, E. Kristofer Gamstedt, A. Pranovich, and A. Rosling, "Studies on mechanical properties of wood fiber reinforced cross-linked starch composites made from enzymatically degraded allylglycidyl ether-modified starch," Composites Part A, vol. 41, no. 10, pp. 1409-1418, 2010.

[15] R. Zhao, P. Torley, and P. J. Halley, "Emerging biodegradable materials: starch- and protein-based bio-nanocomposites," 
Journal of Materials Science, vol. 43, no. 9, pp. 3058-3071, 2008.

[16] A. E. S. Vercelheze, F. M. Fakhouri, L. H. Dall'Antônia et al., "Properties of baked foams based on cassava starch, sugarcane bagasse fibers and montmorillonite," Carbohydrate Polymers, vol. 87, no. 2, pp. 1302-1310, 2012.

[17] E. Azwar, E. Vuorinen, and M. Hakkarainen, "Pyrolysis-GCMS reveals important differences in hydrolytic degradation process of wood flour and rice bran filled polylactide composites," Polymer Degradation and Stability, vol. 97, no. 3, pp. 281-287, 2012.

[18] N. L. Garcia, L. Ribba, A. Dufresne, M. I. Aranguren, and S. Goyanes, "Physico-Mechanical properties of biodegradable starch nanocomposites," Macromolecular Materials and Engineering, vol. 294, no. 3, pp. 169-177, 2009. 

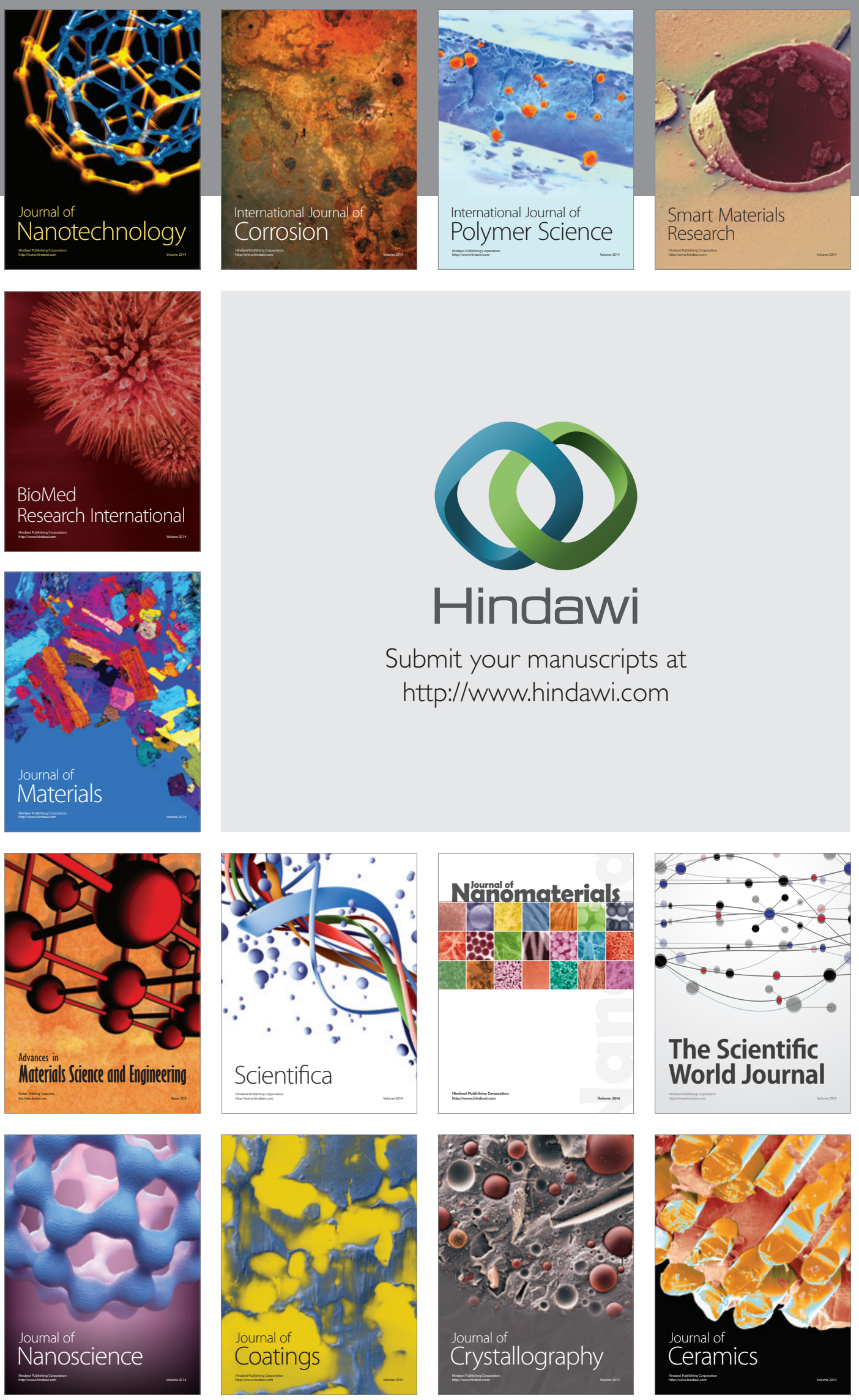

The Scientific World Journal

Submit your manuscripts at

http://www.hindawi.com

\section{World Journal}

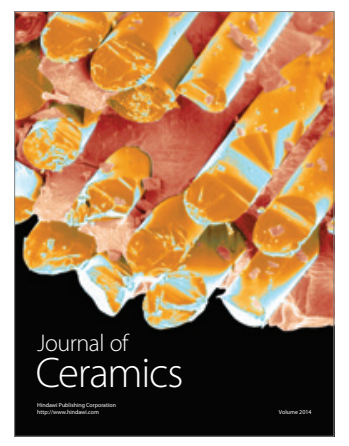

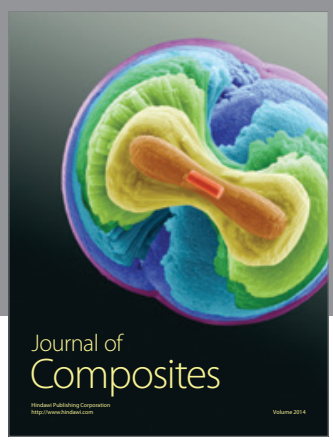
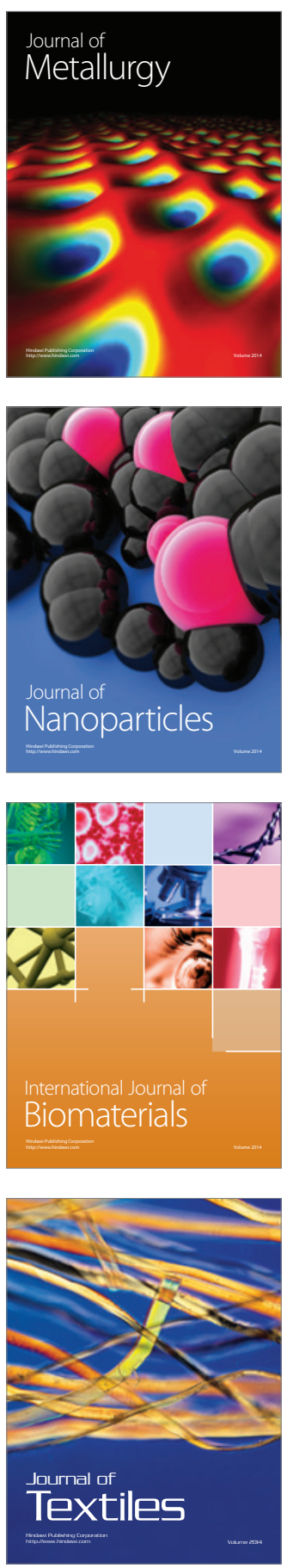